\title{
Application of green zero-valent iron nanoparticles to the remediation of soils contaminated with ibuprofen
}

S. Machado, W. Stawiński, P.Slonina, A.R. Pinto, J.P. Grosso, H.P.A. Nouws,

J.T.Albergaria,C.Delerue-Matos

GRAPHICAL A B STRACT

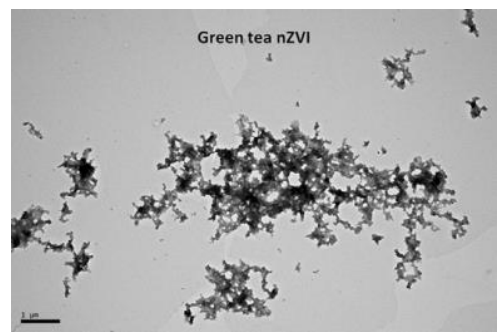

ABSTRACT

Zero-valent iron nanoparticles (nZVIs) are often used in environmental remediation. Their high surface area that is associated with their high reactivity makes them an excellent agent capable of transforming/degrading contaminants in soils and waters. Due to the recent development of green methods for the production of $\mathrm{nZVIs}$, the use of this material became even more attractive. However, the knowledge of its capacity to de- grade distinct types of contaminants is still scarce.

The present work describes the study of the application of green nZVIs to the remediation of soils contami-nated with a common antiinflammatory drug, ibuprofen. The main objectives of this work were to produce nZVIs using extracts of grape marc, black tea and vine leaves, to verify the degradation of ibuprofen in aque- ous solutions by the nZVIs, to study the remediation process of a sandy soil contaminated with ibuprofenusing the nZVIs, and to compare the experiments with other common chemical oxidants.

The produced nZVIs had nanometric sizes and were able to degrade ibuprofen ( 54 to $66 \%$ of the initial amount) in aqueous solutions. Similar remediation efficiencies were obtained in sandy soils. In this case the remediation could be enhanced (achieving degradation efficiencies above 95\%) through the complemen- tation of the process with a catalyzed nZVI Fenton-like reaction. These results indicate that this remediation technology represents a good alternative to traditional and more aggressive technologies.

Keywords:

Ibuprofen, Chemical treatment, Soil remediation, Zero-valent iron nanoparticles, Green production 


\section{Introduction}

Zero-valent iron (ZVI) is a well known remediation agent because of its use in permeable reactive barriers. These barriers are commonly and efficiently used in the treatment of soil and groundwater which have been contaminated with distinct contaminants, such as halogenated hydrocarbons (e.g. trichloroethylene or perchloroethylene) or heavy metals (e.g. arsenic or chromium) (Thiruverikatachari et al., 2008). In the last fifteen years ZVI gained attention of the scientific community because of its utilization as a nanomaterial in the remediation of soils and waters; however, universal acceptance has not yet been achieved (Crane and Scott, 2012). Among the reasons for the lack of acceptance that can be underlined are concerns related to the long-term fate of these particles in the environment, their ecotoxicity and the inexistence of an established, simple and fast production method.

According to Li et al. (2006) there are two general strategies for the production of nZVI: top-down and bottom-up approaches. The topdown approach uses mechanical and chemical processes (ground/ ball milling, etching, and machining) to reduce larger size ZVI (granular, macro- and microsizes). The bottom-up approach promotes the 'growth' of the particles on ZVI through several processes such as chemical synthesis or self-assembling. These methods are generally expensive and require specific equipment. In one of the most widely used bottom-up processes sodium borohydride is used to reduce iron(III) or iron(II) to zero-valent iron nanoparticles (Hoag et al., 2009). This chemical process presents disadvantages related to safety issues associated with the use of a toxic reagent (sodium borohydride) and the formation of a flammable gas (hydrogen) during the process (Li et al., 2006). However, in the last years several authors have been developing a greener bottom-up method that involves the utilization of extracts from natural products (usually leaves or peels) (Hoag et al., 2009; Machado et al., 2013). These extracts have high reductive capacities and assure the reduction of the iron(III)/(II), producing nZVI. The main advantages of this method are related to the use of natural products (that in some cases are considered wastes, e.g. fruit peels or tree leaves) and non-toxic solvents, in this case water. This 'green' method also enhances the stability of the nZVIs through the capping action of the polyphenols present in the extract, which delays the agglomeration process and increases the reactivity and efficiency of the remediation (Hoag et al., 2009). However, this method is not yet universally accepted because of the lack of knowledge of the production method as well as of the nZVIs' characteristics, namely size, agglomeration, and, mainly, their reactivity.

It has been proven that nZVIs are efficient for the degradation of halogenated hydrocarbons (Wang et al., 2012), polychlorinated biphenyls (PCBs) (Petersen et al., 2012) or metals (Zhu et al., 2009), but information about their reactivity with pharmaceutical products (PPs) is scarce. PPs have been massively used and are considered emergent contaminants because they have been introduced in soils and waters through (i) human excretions in sewage collectors (especially from hospital effluents (Heberer, 2002)), (ii) disposal of unwanted, unused or expired products in the toilet or sink, and (iii) land application of animal manure (O'Connor and Aga, 2007) and treated sewage sludge (Kinney et al., 2006). PPs have been detected (at $\mathrm{ng} \mathrm{L}^{-1}$ and $\mu \mathrm{g} \mathrm{L}^{-1}$ levels) in a wide variety of water samples, such as effluents (from medical care units, landfills, and municipal sewage), seawater, drinking water, and surface- and groundwater, (Benotti et al., 2009; Fatta-Kassinos et al., 2011); but also in soils and sediments in concentrations ranging from $\mu \mathrm{g} \mathrm{kg}^{-1}$ to $\mathrm{mg} \mathrm{kg}^{-}$
1 (Braganca et al., 2012; Li et al., 2012). Based on this, and to preserve 
drug and a priority substance that can present significant risk to or via the aquatic environment, according to the European Community (EC), Scientific Committee on Health and Environmental Risks (2011)) using green nZVIs. Experiments with common oxidants (po- tassium permanganate, hydrogen peroxide and Fenton's reagent) were performed in order to compare the results with those obtained with thenZVIs.

\section{Materials and methods}

\subsection{Reagents and solutions}

Ibuprofen $(98 \%(\mathrm{~m} / \mathrm{m}))$ was obtained from Sigma-Aldrich, hydro- gen peroxide $(30 \%(\mathrm{w} / \mathrm{v}))$ and sulphuric acid $(98 \%(\mathrm{w} / \mathrm{w}))$ were pur- chased from Panreac, ammonium iron(II) sulphate hexahydrate and sodium hydroxide were supplied by Pronalab, and iron(III) chloride hexahydrate and potassium permanganate were obtained from Merck. All reagents were of analytical grade or equivalent quality. Type II deionized water (resistivity $=15.0$ $\mathrm{M} \Omega \mathrm{cm}$ ) was used throughout the study and was obtained from an Elix 3 Advantage sys- tem (Millipore). Two ibuprofen solutions were prepared (70 and $10 \mathrm{mg} \mathrm{L}^{-1}$ ) and diluted with water to achieve the desired concentra-

tions. For the remediation experiments solutions of potassium per- manganate $\left(0.0100 \mathrm{~mol} \mathrm{~L}^{-1}\right)$, hydrogen peroxide $(0.880$ $\left.\mathrm{mol} \mathrm{L}^{-1}\right)$, iron(III) $\left(0.100 \mathrm{~mol} \mathrm{~L}^{-1}\right)$, and iron(II) (0.100 $\left.\mathrm{mol} \mathrm{L}^{-1}\right)$ were used.

\subsection{Analysis of ibuprofen}

Ibuprofen was analyzed using liquid chromatography (LC). The LC syswater and soil quality, it is imperative to conduct experiments to study the degradation of these contaminants. In these studies the

use of green nZVIs can become an efficient and sustainable option.

The present work reports the development of a new and more sustainable method for the chemical remediation of water and soil contaminated with ibuprofen (a widely used antiinflammatory tem (JASCO, Inc.) consisted of a quaternary gradient pump (PU-2089P/us), an autosampler (AS-2057Plus), a column oven (CO-2060Plus), and a photodiode array detector (PDA, MD-2018Plus). JASCO ChromNAV software (version 1.17.01) was used to acquire and process all the chromatographic data. For the separations a Phenomenex 2.6 $\mu \mathrm{m} \mathrm{C18} 100 \mathrm{~A}$ $(100 \times 2.10 \mathrm{~mm})$ column was used at $35{ }^{\circ} \mathrm{C}$. The mobile phase consisted of $0.1 \%(\mathrm{v} / \mathrm{v})$ aqueous formic acid $(\mathrm{A})$ and $0.1 \%(\mathrm{v} / \mathrm{v})$ formic acid in acetonitrile $(B)$ using the following linear gradient program (A/B, \% (v/v)): 55/45: 0-3 min, gradient: 3-5 min; 5/95: 5-7 min; gra- dient: 7-8 $\mathrm{min}$; 55/45: 8-20 $\mathrm{min}$. The other instrumental parameters were: injection volume: $20 \mu \mathrm{L}$; flow rate: $0.5 \mathrm{~mL} \mathrm{~min}{ }^{-1}$; and detectionwavelength: $220 \mathrm{~nm}$.

For the quantification of ibuprofen the external standard calibration method was used. Calibration curves between 0.0250 and $10.0 \mathrm{mg} \mathrm{L}^{-1}$ $(0.981 \leq r \leq 0.997)$ were constructed at different $\mathrm{pH}$ values.

\section{3. $n Z$ VI production}

One of the novelties of this work is the utilization of a new generation of nanoparticles: green nZVIs. For their production, extracts from natural products with high reductive powers were used. These extracts can substitute sodium borohydride for the reduction of iron(III). The extracts were produced according to the procedures developed by Machado et al. (2013), using black tea-, grape marc-, and vine leaves. The extractions were performed in a conical flask in a water bath $\left(80{ }^{\circ} \mathrm{C}\right)$ with continuous stirring using the conditions presented in Table 1 . The nZVIs were produced by mixing the obtained extracts with a $0.100 \mathrm{~mol} \mathrm{~L}^{-1}$ iron(III) solution. Spectrometric analysis at

Table 1 Most favorable extraction conditions for the studied products.

\begin{tabular}{|c|c|c|c|}
\hline $\begin{array}{l}\text { Product } \\
\text { content } \\
(\% \pm \mathrm{SD})\end{array}$ & $\begin{array}{l}\text { Moisture } \\
\text { (min) }\end{array}$ & $\begin{array}{l}\text { Contact } \\
\text { time } \\
(\mathrm{g} / 100 \mathrm{~mL})\end{array}$ & $\begin{array}{l}\text { Massleaf:volume } \\
\text { water }\end{array}$ \\
\hline Vine leaves & $5.0 \pm 0.7$ & 80 & 3.7 \\
\hline Black tea leaves & $8.5 \pm 1.0$ & 20 & 0.8 \\
\hline Grape marc & $6.3 \pm 0.8$ & 20 & 3.7 \\
\hline
\end{tabular}


$750 \mathrm{~nm}$ (using a Thermo Evolution300 spectrophotometer) was used to identify the volume ratio of iron(III):extract that assured complete reduction of iron(III) to nZVI (Supplementary data).

To confirm the size and constitution of the nZVIs, the extract-iron(III) mixtures were mounted on 300-mesh nickel grids and examined using a JEOL JEM 1400 transmission electronic microscope (TEM; $120 \mathrm{kV}$ ) (Tokyo, Japan). To determine the size of the produced nZVls, magnification modes of $120,000 \times$ to $500,000 \times$ were used. Fig. 1 shows examples of the obtained TEM images. The analysis confirmed that metallic iron particles were produced, with sizes between 15 and $45 \mathrm{~nm}$. In some cases larger agglomerates were identified (Fig. 1a).

This simple and fast nZVI production method can be performed in-situ, which is an additional advantage of this alternative method.

\subsection{Chemical treatment in aqueous solutions}

In order to evaluate the capacity of the nZVIs to degrade ibuprofen, experiments were performed in ibuprofen-containing $\left(10-\mathrm{mg} \mathrm{L}^{-1}\right)$ aqueous solutions at acidic and neutral $\mathrm{pH}$ values (alkaline solutions were not tested because iron hydroxides precipitate at these $\mathrm{pH}$ values). Furthermore, this concentration not only allowed the evaluation of the remediation of water and soils but also of local degradation where inadequate discharges of ibuprofen have occurred. The experiments were conducted in $250-\mathrm{mL}$ Erlenmeyer flasks with $25 \mathrm{~mL}$ of a $10-\mathrm{mg} \mathrm{L}^{-1}$ ibuprofen solution. A $30-\mathrm{mL}$ volume of extract and the iron(III) solution (1.5; 6.0; and $9.0 \mathrm{~mL}$ for black tea leaves, grape marc, and vine leaves, respectively) were added to the flask simultaneously, achieving in-situ production of nZVI. Considering the results of the antioxidant ca- pacity of the extracts (Machado et al., 2013) and the results of Hoag et al. (2009) it was assumed that all iron(III) was reduced. Final nZVI concentrations of $2.7,9.8$ and $14 \mathrm{mmol} \mathrm{L}^{-1}$ for black tea leaf-, grape marc-, and vine leaf extracts, respectively, were obtained.

After the addition of the extract and iron(III) solution, the flask was capped, to avoid dissolution of atmospheric oxygen that would decrease the nZVIs' reactivity. The solution was continuously stirred for proper mixing. Samples were collected at selected time intervals and analyzed by LC.

Similar tests were also performed (at the same $\mathrm{pH}$ values used for the nZVIs) with potassium permanganate, hydrogen peroxide and Fenton's reagent using different noxidant:nibuprofen ratios. The tests were considered finished when the ibuprofen concentration was below the lower limit of linearity of the calibration curve, when no further reaction was observed or when the reaction between ibupro- fen and the reductant/oxidant stopped. The experiments were performed in duplicate and presented deviations below $5.6 \%$.

\subsection{Chemical oxidation/reduction in a sandy soil}

The sandy soil was purchased from Mibal - Minas de Barqueiros, S.A. (Esposende, Portugal) and was composed of particles with diameters between 0.5 and $1 \mathrm{~mm}$. The soil did not contain detectable organic matter, had a pH of 6.27 and an apparent density of $1.38 \mathrm{~g} \mathrm{~mL}^{-1}$.

Humic substances change the physicochemical properties of the nanoparticles that can result in decreased dispersion or increased aggregation of the nanoparticles (Dong and Lo, 2013). However, when high nZVI concentrations (above $1 \mathrm{~g} / \mathrm{L}$ ) are used, aggregation and deposition can be the dominant mechanism of removal in comparison to particle-soil interactions because of the increase of particle/particle interactions (Phenrat et al., 2009). Kim et al. (2012) suggest that humic acids induce various effects on the reactivity of nZVIs, such as the inhibition of the readsorption of the released iron, the improvement of the iron dissolution, the enhancement of the electron transfer, and the accumulation of humic acids that could originate clogging.

Before the remediation tests, the soil was prepared in order to induce the desired ibuprofen contamination $\left(2.8 \mathrm{mg} \mathrm{kg}^{-1}\right)$ : (i) drying of the soil at $105{ }^{\circ} \mathrm{C}$ (for $24 \mathrm{~h}$ ), (ii) addition of standard ibuprofen solution (70 $\mathrm{mg} \mathrm{L}^{-1}$ ) to induce a contamination of $2.8 \mathrm{mg} \mathrm{kg}^{-1}$, and (iii) homogenization of the soil. At the same time a non-contaminated soil was prepared following the same procedure, replacing the ibuprofen solution with deionized water.

The soil tests were performed in glass tubes (i.d.: $2.5 \mathrm{~cm}$; $\mathrm{h}: 14.5 \mathrm{~cm}$ ) in which $50 \mathrm{~g}$ of contaminated soil was placed. The tests with the nZVIs were performed by simultaneously adding 10 $\mathrm{mL}$ of extract and the iron(III) solution (3.0; 2.0; and $0.50 \mathrm{~mL}$ for vine leaves, grape marc, and black tea leaves, respectively (Machado et al., 2013)) at the top of the tube, allowing the percolation of the mixture through the soil. The degradation process was monitored after $1 \mathrm{~h}$ and then daily for the following 7 days. A similar procedure was followed for the experiments using Fenton's reagent. In this case the degradation process was only evaluated once: $1 \mathrm{~h}$ after the addition of the reagents.

The quantification of the concentration of ibuprofen that remained in the soil was performed after the extraction of ibuprofen from the soil matrix. Complete extraction was assured by (i) the addition of $30 \mathrm{~mL}$ of water to $50 \mathrm{~g}$ of contaminated soil $\left(2.8 \mathrm{mg} \mathrm{kg}^{-1}\right)$, followed by (ii) stirring for $30 \mathrm{~min}$. This proves that, as expected, no ibuprofen remained adsorbed on the sandy soil's surface (Xu et al., 2009). To avoid injection of suspended particles into the LC system, the final so- lution was centrifuged for $5 \mathrm{~min}$ at $4500 \mathrm{rpm}$ prior to injection.

The experiments were performed in duplicate and presented deviations below $7.2 \%$. 


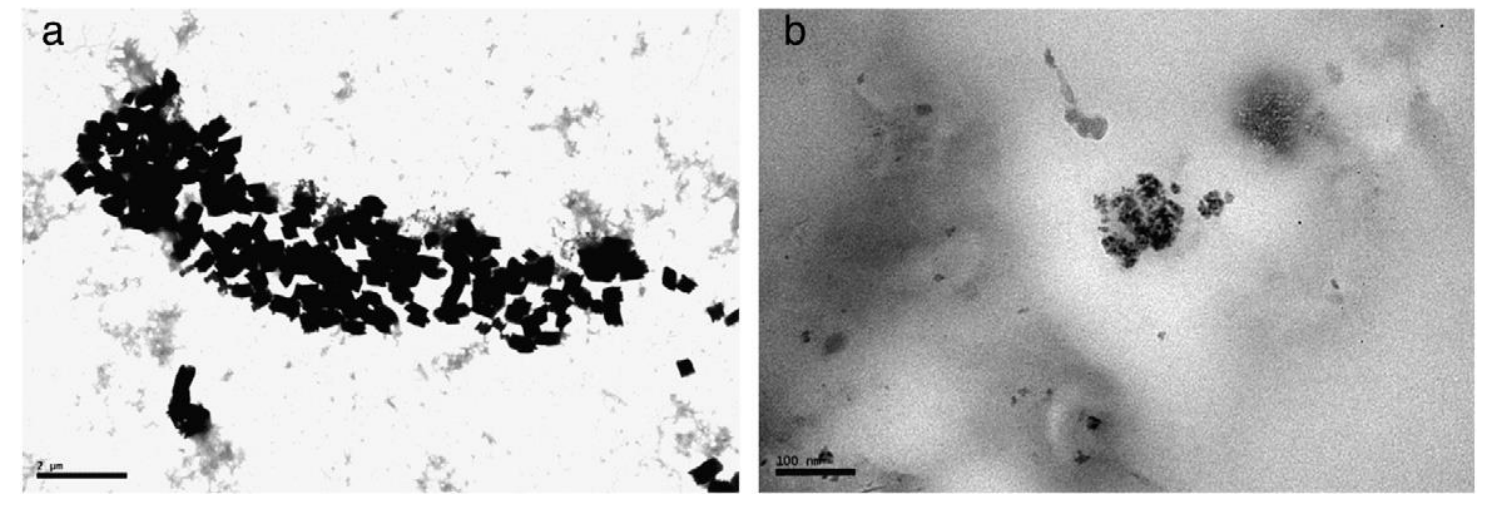

Fig. 1. Representative TEM images of the nZVIs synthesized using (a) vine and (b) black tea extracts. 
3. Results and discussion

\subsection{Degradation of ibuprofen in aqueous solution}

The results of the remediation of aqueous solutions of ibuprofen, at different $\mathrm{pH}$ values ( 3 and 7 ), are presented in Fig. 2. This $\mathrm{pH}$ range includes the $\mathrm{pH}$ values of distinct water samples as well as landfill leachates. For example, the $\mathrm{pH}$ of 'young' landfill leachates is around 4.5-6.5 (Kurniawan et al., 2010). The upper value was limited by the precipitation of iron hydroxide.

The reaction process between the nZVI surface and the contaminant can be divided in two stages. The first stage occurs during the initial phase of the reaction when the nZVI's surface is extremely reactive, making this stage fast and efficient. As the reaction continues the surface is oxidized, passing to the second stage, where the nZVI's capacity to react is limited by the electron transfer from the core of the nZVI to its surface (Li et al., 2006). In this work the first stage occurred within the first hour of reaction at degradation rates between 3.0 and $4.2 \mathrm{mg} \mathrm{h}^{-1}$. During the second stage much lower degradation rates were observed (from 4.2 to $11 \mu \mathrm{g} \mathrm{h}^{-1}$ ). The second stage was influenced by the $\mathrm{pH}$ of the solution; the degradation rate decreased at $\mathrm{pH} 7$ when compared to the ones obtained at $\mathrm{pH} 3$. For grape marc extracts it decreased from 10 to $6.1 \mu \mathrm{g} \mathrm{h}^{-1}$ and for vine leaf ex- tracts from 7.3 to $5.6 \mu \mathrm{g} \mathrm{h}{ }^{-1}$. However, in the experiments performed with the nZVIs produced using black tea leaf extracts no influence of the $\mathrm{pH}$ on the degradation rate (11 and 10 $\mu \mathrm{g} \mathrm{h}^{-1}$ for $\mathrm{pH} 3$ and 7 , re- spectively) was detected.

Comparing the degradation efficiencies, no significant differences were observed in the experiments with vine leaf- and grape marc extracts while in the experiments with the black tea leaf extract a higher efficiency was obtained at $\mathrm{pH} 7$ (an increase from 51 to 66\%). This could be related not only to the reactive capacity of the produced nZVI but also to their stability in the extract during the remediation process. In the experiments at $\mathrm{pH} 3$, grape marc- and black tea ex- tracts presented similar degradation efficiencies ( 32 and $30 \%$, respec- tively) after the first hour of treatment. Vine leaf extracts degraded $42 \%$ of the initial amount of ibuprofen in the solution. This could be related to the higher nZVI concentration (14 $\mathrm{mmol} \mathrm{L}^{-1}$ ) in these ex- tracts. In the experiments performed at $\mathrm{pH} 7$, and after the first hour

of reaction, similar efficiencies were achieved except for the test with grape marc extracts that presented an increase of $41 \%$. This behavior could also be related to the chemical stability of the complex grape marc extract matrix.

The results show that the green nZVIs were able to degrade ibuprofen and proved the potential of this remediation agent. The decrease of the nZVIs' reactivity during the process is the biggest limitation of this method. Nevertheless, there are other technologies that can be used to complement this method and turn it attractive. This will be discussed further on (Section 3.3).

Similar tests were performed with potassium permanganate, hydrogen peroxide and Fenton's reagent to evaluate the capacity of these oxidants to degrade ibuprofen and to compare the results with those obtained with nZVI. Potassium permanganate and hydrogen peroxide were not able to degrade ibuprofen at the studied $\mathrm{pH}$ values, even when high ibuprofen:oxidant molar ratios (1:25 for potassium permanganate and 1:166 for hydrogen peroxide) were used. However, Fenton's reagent degraded ibuprofen very fast but required significant amounts of reagents. The results obtained for aqueous ibuprofen solutions ( $\mathrm{pH} 3$ and 7) are presented in Fig. 3.

These results show that ibuprofen can be degraded not only through reduction processes (using the nZVIs) but also through oxidation processes using Fenton's reagent. At pH 3, and using an ibuprofen:iron(II):hydrogen peroxide molar ratio of 1:3.5:31, the degradation was almost complete (>98\%) after $2 \mathrm{~min}$. At $\mathrm{pH} 7$ the most appropriate molar ratio is 1:31:274. Some of the oxidation products of ibuprofen are proposed in other works (Sabri et al., 2012; Scheers et al., 2012), but the reaction pathways are not fully known.

Based on the results it can be concluded that the tested natural products can be used for the production of nZVIs, which in turn can be used for the degradation of ibuprofen in aqueous systems. The use of grape marc and vine leaves is especially attractive because, unlike black tea leaves, they are considered valueless wastes. However, further efforts should be focused on the nZVI production in order to produce more concentrated extracts and therefore reduce the volume of reagents required.

\subsection{Degradation of ibuprofen in a sandy soil}

The remediation experiments were performed using a contaminated sandy soil ( $2.8 \mathrm{mg}$ ibuprofen $\mathrm{kg}^{-1}$ ). The extract (from grape marc, black tea- or vine leaves) and the iron(III) solution were added at the top of the soil column and allowed to percolate through the soil matrix. The degradation efficiencies achieved during these tests are presented in Fig. 4.

After the addition of the extract and the iron(III) solution the soil acquired a pH value near 3. Comparing Figs. 2 and 4, it can be observed that, as occurred in aqueous solutions, the vine leaf extract presented the highest degradation efficiencies (62\%) and the black tea leaf extract presented the lowest (36\%). Thus, it can be concluded that at lower $\mathrm{pH}$ values the $\mathrm{nZVIs}$ produced with vine leaf extracts are the most appropriate to degrade ibuprofen. Furthermore, it can be stated that the degradation of the contaminant in the soil occurs slower. This is due to the difficulties that the nZVIs have to percolate through the soil, needing more time to contact/react with the contaminant located in deeper 

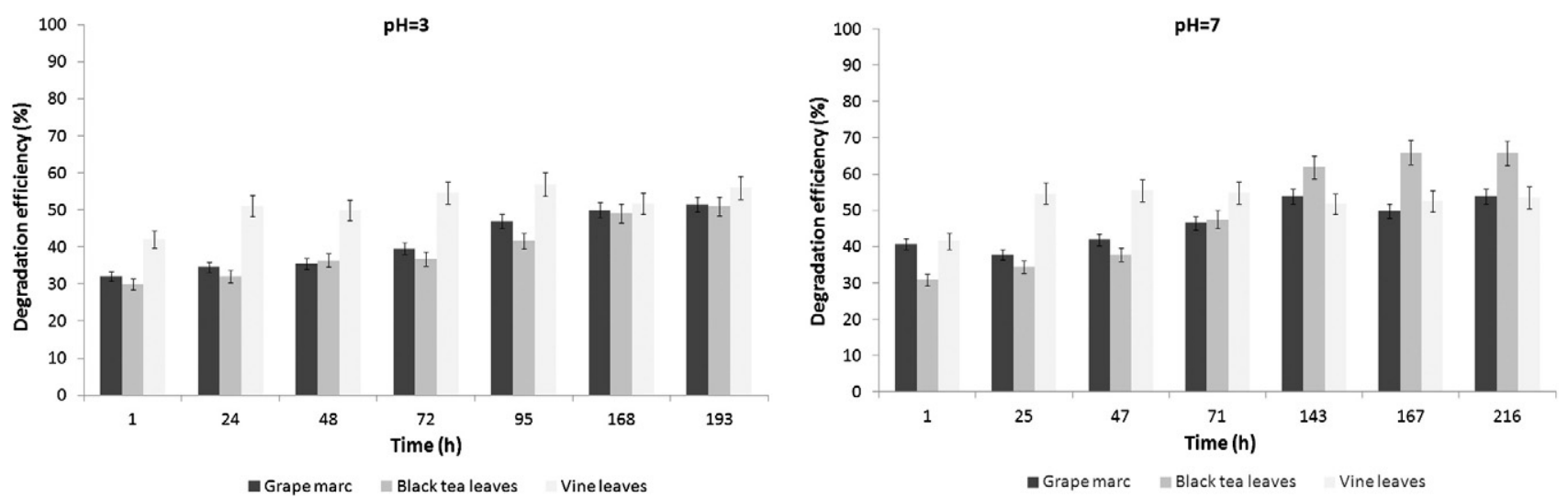

Fig. 2. Efficiencies of ibuprofen degradation in aqueous solution using nZVIs produced from different extracts (nZVI concentrations of 2.7, 9.8 and $14 \mathrm{mmol} \mathrm{L}^{-1}$ for tea leaves, grape marc, and vine leaves, respectively) at different $\mathrm{pHs}(3$ and 7$)$. 

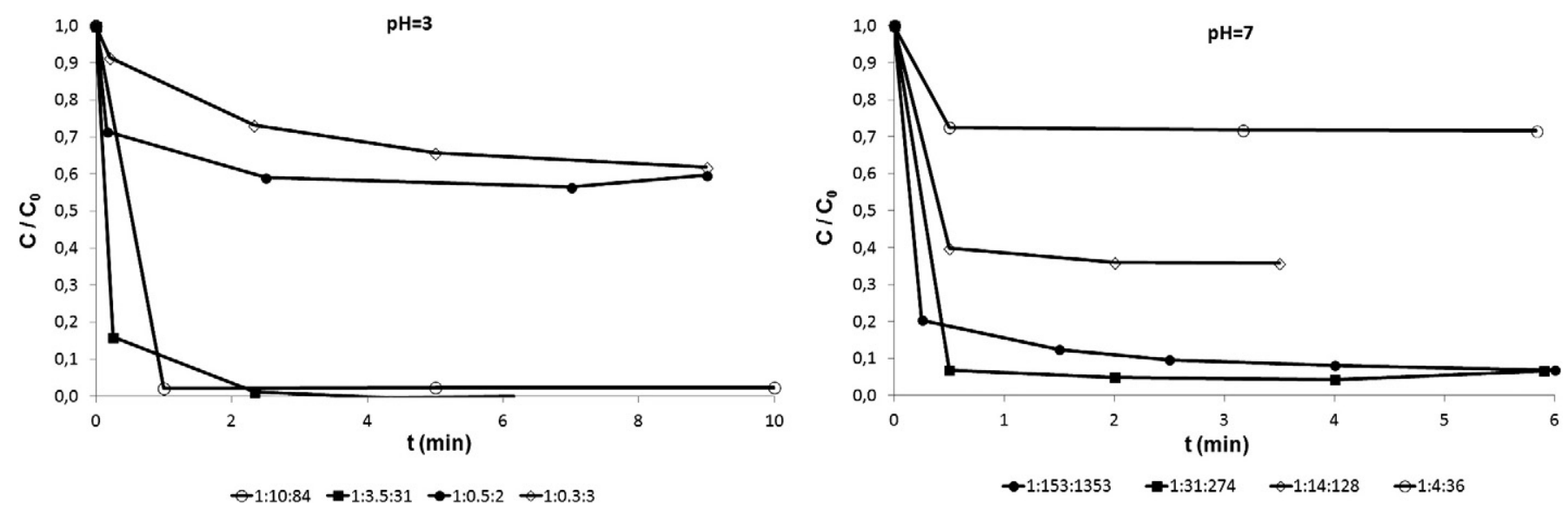

Fig. 3. Degradation level of ibuprofen in aqueous solution using different ibuprofen:iron(II):hydrogen peroxide molar ratios.

zones (Schrick et al., 2004; Phenrat et al., 2007). The degradation firstly occurs at the more superficial zone of the soil and, as the nZVIs move downwards, its surface oxidizes through the reaction with ibuprofen and oxygen, located in the soil pores or dissolved in the soil moisture, decreasing their reactivity. This behavior not only affected the initial degradation rate but also, in the experiment with nZVI obtained with black tea leaves, the overall degradation efficiency, decreasing $15 \%$. For the other extracts no significant changes were observed: an increase of $6 \%$ for vine leaves (reaching 62\%), and a decrease of $3 \%$ for grape marc (to $48 \%$ ). All these values indicate that the use of $\mathrm{nZVIs}$, and especially the ones produced using a green method, can become a sustainable, easy and efficient technology for remediation of soils contaminated with pharmaceutical products. According to Hoag et al. (2009) the impact of the extracts on soils is reduced because of their biodegradability and low toxicity. It is also clear that there is a need for further studies concerning the application of this technology to soils in order to improve the nZVIs' transport through the soil matrix and consequently the degradation rate and the process efficiency.

Fenton's reagent was also used for soil remediation. The soil tests started with the molar ratio identified in the aqueous tests as the most fast/efficient (1:31:274), achieving a degradation of $69 \%$, after $1 \mathrm{~h}$ of reaction. The short life of the $\mathrm{OH} \bullet$ radical did not allow the reaction to occur at deeper zones, explaining the observed decrease in the degradation efficiency. A similar test was performed with a 10 fold of the reagents quantity (molar ratio of 1:310:2740) which led to a degradation efficiency of $86 \%$. In a third test, using a molar ratio of 1:775:6850, all the added ibuprofen was degraded. From these ex-periments it can be concluded that because of higher ratios (i.e.

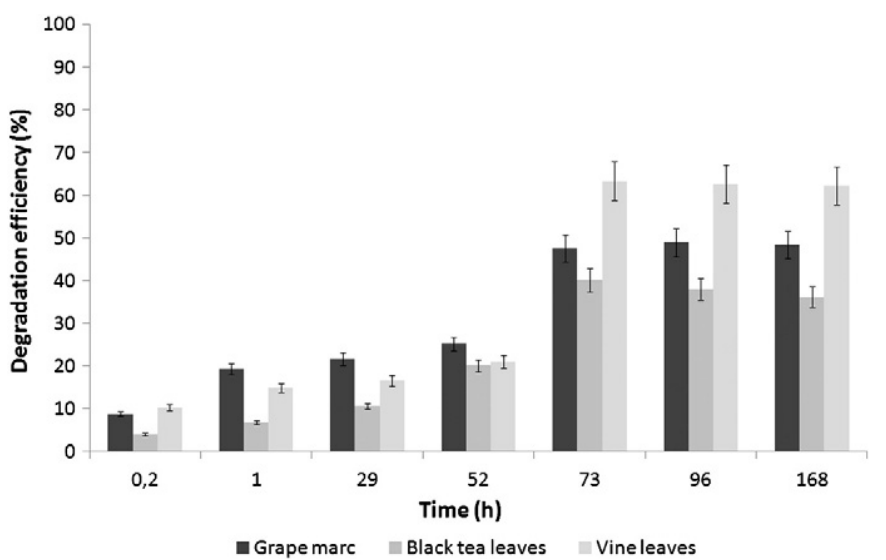

Fig. 4. Degradation efficiencies of the chemical reduction tests using nZVIs performed in sandy soils contaminated with ibuprofen $\left(2.8 \mathrm{mg} \mathrm{kg}^{-1}\right)$. 
higher reagent volumes), and a sandy soil was used, deeper zones of the soil were reached in a shorter period of time assuring the deg- radation of ibuprofen.

This demonstrates the limitation of the application of Fenton's re- agent to contaminated soils as well as the high amounts of reagents required to achieve the remediation compared to those needed for aqueouscontaminations.

\subsection{Degradation of ibuprofen using a catalyzed nZVI Fenton-like} reaction

As was stated before, in order to turn the application of nZVI for the remediation of water or soils more competitive and attractive comple- mentary actions are needed to increase the degradation efficiency. The addition of hydrogen peroxide to perform a nZVI catalyzed Fenton reaction is a possible complementary action that was successfully tested by Hoag et al. (2009) to degrade bromothymol blue. Accordingly, and after the remediation of waters and soils with $\mathrm{nZVI}$, hydrogen peroxide was added in order to achieve complete degradation of the remaining ibuprofen. The results are presented in Fig. 5 and it can be seen that in almost all the tests (except for the test performed in soils with black tea leaf extracts) it was possible to degrade up to $95 \%$ of ibuprofen with the addition of hydrogen peroxide. These results indicate that the degradation process can be enhanced by the Fenton reaction and that the degradation capacity was proportional to the amount of iron(III) added to the soil/aqueous solution. This is confirmed by the obtained results: lower efficiencies were obtained in the experiment with nZVI produced with black tea leaves where a lower amount of iron(III) was used. Higher efficiencies were obtained in the experiments with $\mathrm{nZVI}$ produced with grape marc- and vine leaf extracts where higher amounts of iron(III) were used. The results also suggest that it is advisable to use slightly higher amounts of iron(III) in the production of the nZVIs in order to, in a first stage, assure maximum nZVI production, and, in a second stage, to guarantee the presence of a sufficient amount of remaining iron(III) to complete the remediation.

Fenton's reagent is widely used, well known, easy to apply, and al- lows fast remediation (Cao et al., 2013). However, it is common that issues like iron precipitation, gas formation, and clogging of the injec- tion wells, related to the injection of iron(II) and hydrogen peroxide into the soil, arise. Additionally, the use of nZVIs implies less toxic re- agents and the enhancement of biological processes in the soil through the addition of a nutrient source (the extract). However the use of nZVIs is poorly studied and its application has several unsolved issues concerning (i) the movement of the nZVIs through the soil ma- trix and, consequently, the warranty that the reaction with all the contaminant located in the contaminated area occurs; and (ii) the lack of knowledge of the effectiveness of the nZVIs to degrade specific contaminants. 
a

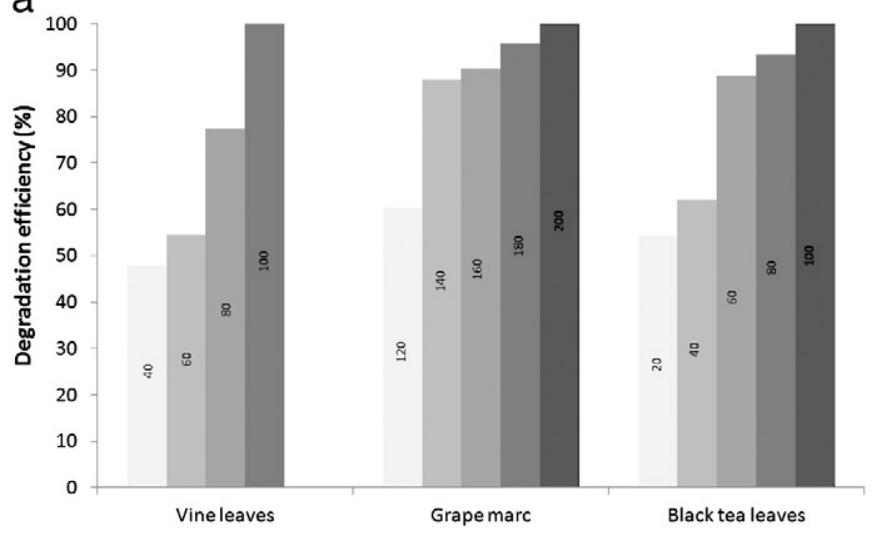

b

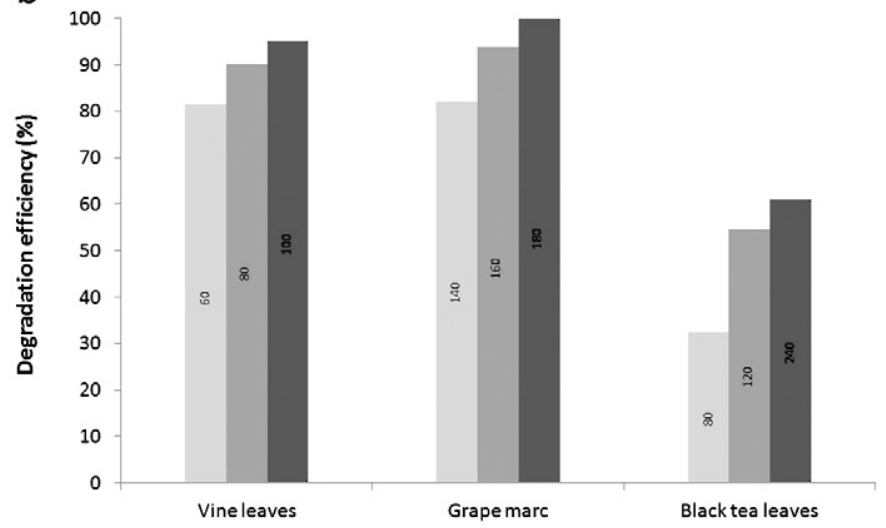

Fig. 5. Degradation efficiencies obtained after the addition of different volumes of hydrogen peroxide (3\%) after the nZVI application in the aqueous tests (a) (in $\mu \mathrm{L}$ per $\mathrm{mL}$ of con- taminated sample) and soils (b) (in $\mu \mathrm{L}$ per g of contaminated sample).

In order to compare both treatments in aqueous solutions as well as in soils, the amount of reagents needed to each remediation was calculated (Table 2).

Table 2 shows that the utilization of Fenton's reagent for the remediation of aqueous solutions uses lower amounts of reagents while for soil remediation the nZVI process is more economical. These differences can be related to the persistency of the reactive form of the re- agent; the $\mathrm{OH} \bullet$ radical reacts rapidly (in minutes or a few hours) and loses its reactivity while the $\mathrm{nZVI}$ is more persistent (maintaining its reactivity for days) extending the reaction (Huling and Pivetz, 2006). These results reinforce the potential that green nZVIs have in environmental remediation, not only because of the use of a greener and more sustainable production method, but also because of their extremely attractive behavior when applied to soils, compared to tra- ditional chemical reaction reagents. Therefore, the nZVIs could be- come accepted remediation agents.

\section{Conclusions}

The results presented in this paper allow the conclusion that it is possible to produce green nZVIs with sizes ranging from 15 to 45 $\mathrm{nm}$ using extracts from grape marc, black tea and vine leaves. These nanoparticles degraded 50 to $65 \%$ of ibuprofen in aqueous solutions (with different $\mathrm{pHs}$ ). The nZVIs produced using black tea leaf extracts presented the best results at $\mathrm{pH} 7$ and the $\mathrm{nZVIs}$ produced using vine leaf extracts presented the best results at $\mathrm{pH} 3$. The tests with sandy soils contaminated with ibuprofen showed that the degradation process is slower than in aqueous systems but without a significant impact on the overall degradation efficiency, except for nZVIs produced with black tea leaf extracts, where a decrease of $15 \%$ was observed. The complementation of the remediation using $\mathrm{nZVI}$ with a nZVI catalyzed Fenton-like reaction achieved degradation efficiencies up to $95 \%$, showing the potential of this remediation strategy.

When compared to the traditional chemical oxidation remediation used in this work, the nZVI remediation presented excellent
$\mathrm{nZVI}$

\begin{tabular}{|c|c|c|c|c|}
\hline$n \mathrm{Fe}(\mathrm{II})(\mathrm{mc}$ & $\mathrm{n} \mathrm{H} 2 \underline{2}$ & (mol) & $\mathrm{Fe}(\mathrm{III})(\mathrm{mol})$ & $\mathrm{n} \mathrm{H} 2 \underline{2} \underline{2} \underline{2}$ \\
\hline Aquم & $10^{-6}$ & 5 & $0-4$ & - \\
\hline Aqueous & $4.2 \times 100$ & $7 \times 10$ & $\begin{array}{l}9.0 \times 10 \\
1.5 \times 10^{-4} \\
1.5 \times 10^{-4}\end{array}$ & $\begin{array}{l}8.8 \times 10^{-4} \\
1.8 \times 10^{-5}\end{array}$ \\
\hline Soil & $5.3 \times 10^{-3}$ & $4.6 \times 10^{-3}$ & $\begin{array}{l}3.0 \times 10^{-4} \\
2.0 \times 10^{-4}\end{array}$ & $\begin{array}{l}8.8 \times 10^{-5} \\
1.6 \times 10^{-4}\end{array}$ \\
\hline
\end{tabular}

Table 2

Amounts of iron and hydrogen peroxide required for the 
results, achieving similar degradation efficiencies but using a greener remediation agent (green $\mathrm{nZVI}$ ) and supplying better conditions for a post bioremediation phase through the addition of a nutrient source (the natural extract).

Supplementary data to this article can be found online at http:// dx.doi.org/10.1016/j.scitotenv.2013.05.016.

\section{Acknowledgments}

This work has been financially supported by the "Fundação para a Ciência e a Tecnologia (FCT)" through projects PEst-C/EQB/LA0006/ 2011, PTDC/ECM/103141/2008, and PTDC/AAG-TEC/2692/2012, and the pos-doc grant of J.G. Pacheco (SFRH/BPD/73943/2010).

\section{References}

Benotti MJ, Trenholm RA, Vanderford BJ, Holady JC, Stanford BD, Snyder SA. Pharma- ceuticals and endocrine disrupting compounds in US drinking water. Environ Sci Technol 2009;43:597-603.

Braganca I, Placido A, Paiga P, Domingues VF, Delerue-Matos C. QUEChERS: a new sam- ple preparation approach for the determination of ibuprofen and its metabolites in soils. Sci Total Environ 2012;433:281-9.

Cao MH, Wang LL, Wang L, Chen J, Lu XH. Remediation of DDTs contaminated soil in a novel Fenton-like system with zerovalent iron. Chemosphere 2013;90:2303-8.

Crane RA, Scott TB. Nanoscale zero-valent iron: future prospects for an emerging water treatment technology. J Hazard Mater 2012;211:112-25.

Dong HR, Lo IMC. Influence of humic acid on the colloidal stability of surface-modified nano zero-valent iron. Water Res 2013;47:419-27.

European Community (EC), Scientific Committee on Health and Environmental Risks. Chemicals and the water framework directive: draft environmental quality stan- dards ibuprofen. European Union; 2011.

Fatta-Kassinos D, Meric S, Nikolaou A. Pharmaceutical residues in environmental wa- ters and wastewater: current state of knowledge and future research. Anal Bioanal Chem 2011;399:251-75.

Heberer T. Occurrence, fate, and removal of pharmaceutical residues in the aquatic en- vironment: a review of recent research data. Toxicol Lett 2002;131:5-17.

Hoag GE, Collins JB, Holcomb JL, Hoag JR, Nadagouda MN, Varma RS. Degradation of bromothymol blue by 'greener' nano-scale zero-valent iron synthesized using tea polyphenols. J Mater Chem 2009;19:8671-7.

Huling SG, Pivetz B. In Situ Chemical Oxidation - Engineering Issue, EPA/600/R-06/072. United States Environmental Protection Agency 2006.

Kim DG, Hwang YH, Shin HS, Ko SO. Humic acid characteristics and effects on the reac- tivity of nano-scale zero-valent iron particles during nitrate reduction. Desalin Water Treat 2012;49:147-56.

Kinney CA, Furlong ET, Zaugg SD, Burkhardt MR, Werner SL, Cahill $J D$, et al. Survey of organic wastewater contaminants in biosolids destined for land application. Envi- ron Sci Technol 2006;40:7207-15.

Kurniawan TA, Lo WH, Chan G, Sillanpaa MET. Biological processes for treatment of landfill leachate. J Environ Monit 2010;12:2032-47.
Li XQ, Elliott DW, Zhang WX. Zero-valent iron nanoparticles for abatement of environ- mental pollutants: materials and engineering aspects. Crit Rev Solid State Mater Sci 2006;31:111-22.

Li WH, Shi YL, Gao LH, Liu JM, Cai YQ. Occurrence of antibiotics in water, sediments, aquatic plants, and animals from Baiyangdian Lake in North China. Chemosphere 2012;89:1307-15. 
Machado S, Pinto SL, Grosso JP, Nouws HPA, Albergaria JT, DelerueMatos C. Green pro- duction of zero-valent iron nanoparticles using tree leaf extracts. Sci Total Environ 2013;445-446:1-8.

O'Connor S, Aga DS. Analysis of tetracycline antibiotics in soil: advances in extraction, clean-up, and quantification. TrAC Trends Anal Chem 2007;26:456-65.

Petersen EJ, Pinto RA, Shi XY, Huang QG. Impact of size and sorption on degradation of trichloroethylene and polychlorinated biphenyls by nano-scale zerovalent iron. J Hazard Mater 2012;243:73-9.

Phenrat T, Saleh N, Sirk K, Tilton RD, Lowry GV. Aggregation and sedimentation of aque- ous nanoscale zerovalent iron dispersions. Environ Sci Technol 2007;41:284-90.

Phenrat T, Long TC, Lowry GV, Veronesi B. Partial oxidation ("aging") and surface mod- ification decrease the toxicity of nanosized zerovalent iron. Environ Sci Technol 2009;43:195200.

Sabri N, Hanna K, Yargeau V. Chemical oxidation of ibuprofen in the presence of iron species at near neutral pH. Sci Total Environ 2012;427:382-9.
Scheers T, Appels L, Dirkx B, Jacoby L, Van Vaeck L, Van der Bruggen $B$, et al. Evaluation of peroxide based advanced oxidation processes (AOPs) for the degradation of ibu- profen in water. Desalin Water Treat 2012;50:189-97.

Schrick B, Hydutsky BW, Blough JL, Mallouk TE. Delivery vehicles for zerovalent metal nanoparticles in soil and groundwater. Chem Mater 2004;16:2187-93.

Thiruverikatachari R, Vigneswaran S, Naidu R. Permeable reactive barrier for ground- water remediation. J Ind Eng Chem 2008;14:145-56.

Wang Q, Jeong SW, Choi H. Removal of trichloroethylene DNAPL trapped in porous media using nanoscale zerovalent iron and bimetallic nanoparticles: direct obser- vation and quantification. J Hazard Mater 2012;213:299-310.

Xu J, Wu LS, Chang AC. Degradation and adsorption of selected pharmaceuticals and personal care products (PPCPs) in agricultural soils. Chemosphere 2009;77: 1299-305.

Zhu HJ, Jia YF, Wu X, Wang H. Removal of arsenic from water by supported nano zero-valent iron on activated carbon. J Hazard Mater 2009;172:1591-6. 